\section{Late rust needs no control}

Postharvest defoliation by prune rust did not adversely affect dry yield or fruit quality in the current or following seasons in our experiments. In both orchards, the significant differences among treatments were few, minor and inconsistent. Differences in postharvest defoliation among our treatments were not reflected in dissimilarities in yields the following season. If accelerated postharvest leaf loss was deleterious to the next crop, this effect was overshadowed by other horticultural factors, such as alternate bearing, and was not detected by our experiments. Although we selected orchards whose histories and locations indicated that preharvest defoliation by prune rust was likely, such leaf loss did not occur during the course of these experiments. Consequently we were not able to corroborate the yield losses attributed to preharvest defoliation by prune rust in other regions.

The history and pattern of prune rust in orchards should be considered in making treatment decision for control of this disease. Orchards with histories of early rust infection, or those situated along rivers or in high rainfall areas, should be treated annually for control of prune rust. Such orchards need protection from severe early preharvest defoliation and the associated yield losses that have been reported elsewhere. However, orchards in which rust infection and leaf loss are late-season events should not require treatment to control prune rust. Such late-season defoliation, even though repeated annually, does not appear to harm crop yield or quality.

Mancozeb (not registered for use on prunes in California) was superior to sulfur for control of prune rust.

\section{B.L. Teviotdale is Extension Plant Pa-} thologist, D.M. Harper was Staff Research Associate, and T:J. Michailides is Associate Professor, all of UC Davis, stationed at Kearney Agricultural Center, Parlier; and G.S. Sibbett is Farm Advisor, Tulare County Cooperative Extension.

The authors wish to thank the Prune Marketing Board for financial support of this research.

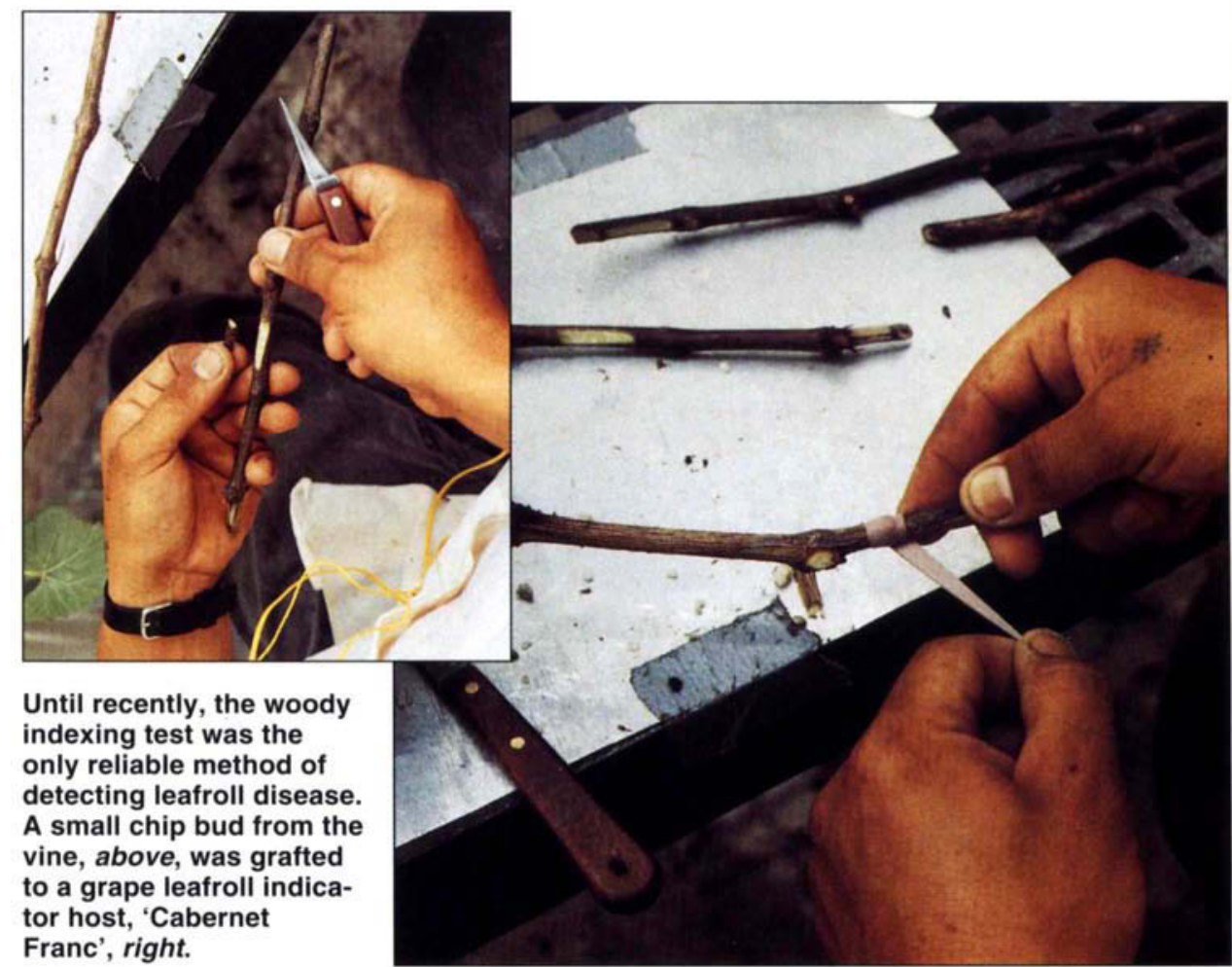

\title{
ELISA test reveals new information about leafroll disease
}

\author{
Adib Rowhani $\square \quad$ Deborah A. Golino
}

The California Grapevine Certification Program has been based on two assumptions about leafroll disease in grapevines: that the disease does not spread signiffcantly in the field in California and that the viruses that cause the disease are evenly distributed in infected vines. Careful testing of the Foundation Plant Materials Service vineyards at Davis using a new ELISA test suggests that these assumptions are not true. Changes in the California Grapevine Certification Program are underway as a result of this new information.
Virus diseases of grapevines can cause serious losses in vineyards. Because these diseases are easily spread with propagation wood when vineyards are planted, and because viruses cannot be eliminated from vineyards once plants are infected, a major virus control technique is the production of disease-tested, certified grapevines by California nurseries. This is currently done in conjunction with UC's Foundation Plant Materials Service (FPMS) and the California Department of Food and Agriculture (CDFA). Research to improve the techniques used to detect grapevine viruses has resulted in faster, more reliable tests for the certification program and in ever-higher 


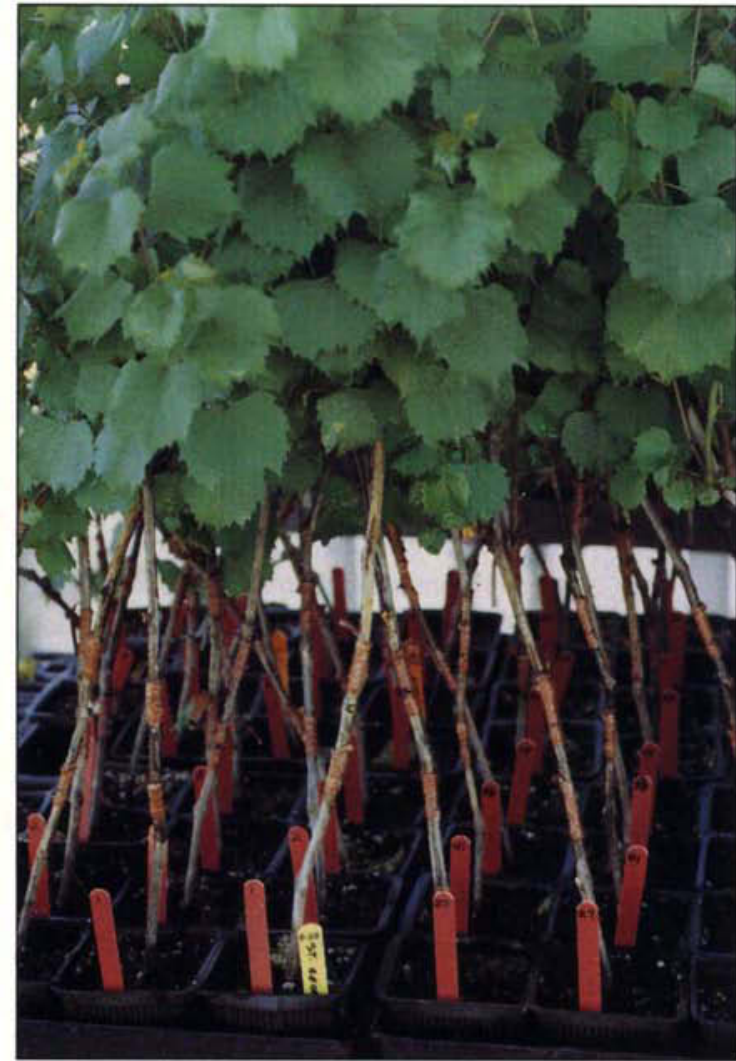

Chip budded indicators in flat await planting in field.

quality standards for the materials produced.

Today there is special interest in testing and detection techniques for the viruses associated with grapevine leafroll disease. Recent advances in our ability to test for some of these viruses have resulted in the discovery that many of our old assumptions about the biology of grapevine leafroll may be incorrect. Furthermore, tests of the grapevines at the older FPMS vineyards have revealed that some vines are leafroll-positive. Although that vineyard has been eliminated from the program, it is essential that we understand how it became infected so that the current collection can be protected. Research is needed to provide more information on leafroll biology so that the California grape industry can be assured of the best possible quality of certified grape nursery stock.

\section{Detection of leafroll disease}

Visual diagnosis of leafroll in leafroll-infected vines is not reliable. Symptoms of leafroll vary with the virus isolate, time of year, grape varieties and environmental conditions.

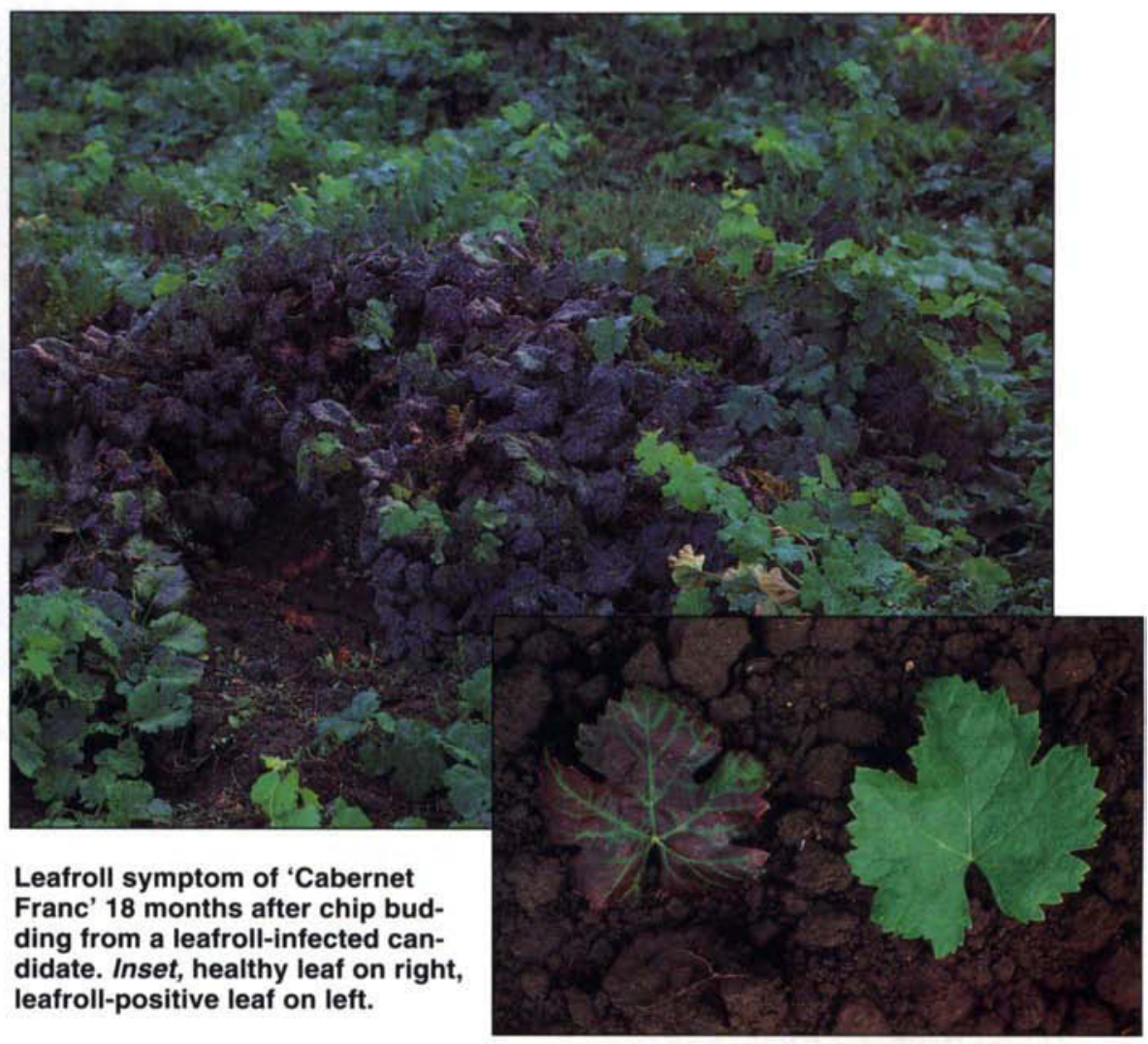

Leafroll symptoms are visible on some varieties from late summer until the time of the first frost. Other varieties may harbor the virus, but not show disease symptoms.

Until recently, the only reliable method of testing for leafroll disease has been to use a woody indexing test. A small chip bud from the selection to be tested (the candidate vine) is grafted to a grape leafroll indicator host, Vitis vinifera 'Cabernet Franc'. If the disease is present in the candidate vine, the Cabernet Franc indicator shows its typical fall leaf symptoms for leafroll: downward rolling of the leaves from the margins and red coloration in the interveinal areas, with veins remaining green until just before leaf fall. Although sensitive and dependable, this test is not completely satisfactory because it is comparatively expensive, it requires 2 years to complete, and the results may be affected by various environmental parameters that are difficult to control.

Other tests are being developed for leafroll disease. However, progress has been slowed by the discovery that leafroll is apparently caused by many different viruses, known as the grapevine leafroll-associated viruses (GLRaVs). To date, seven different viruses have been found to be associated with leafroll, and there is good evidence that more will be discovered. Molecular tests for a virus are specific to each virus, so a separate test must be developed for each leafroll-associated virus. Unfortunately, this work is not yet complete.

ELISA (enzyme-linked immunosorbent assay) tests have been developed for some of the grapevine leafroll-associated viruses. ELISA is one of the most widely used tests for plant viruses. A rapid, sensitive and reliable serological laboratory test that requires only 2 days to complete, ELISA is considered reliable for detection of grapevine fanleaf virus and tomato ringspot virus in grapevines under controlled conditions. The success of using these ELISA tests as part of the California Grapevine Certification Program has generated interest in adding ELISA tests for the grapevine leafroll-associated viruses to the tests used in the program. Although tests are not yet available for all the leafroll 
viruses, each test that can be standardized and integrated into the program represents a step forward.

ELISA results can be affected by the type of tissue being tested (leaf, petiole, root, etc.) and by the time of year when samples are collected. Most GLRaVs are reported to be phloem-associated. Some preliminary research data shows that the samples collected from the petiole and leaf base of mature leaves and from bark scrapings from dormant canes have the highest virus titer. In contrast, young leaves and shoot tips, especially if collected early in the growing season, have very low virus titers; in some instances, virus cannot be detected.

\section{Leafroll at FPMS}

In the fall of 1992, one vine of each of the registered selections at the FPMS was tested by ELISA for GLRaV types II, III and IV. Each of these selections was propagated from a single grapevine of a valuable variety or from a clone that qualified as foundation stock. The test provided a first survey of the GLRaV ELISA status of the foundation vineyard. The preliminary results indicated that about $20 \%$ of the tested vines were infected with at least one of the leafroll-associated viruses. All the ELISA-positive vines were in the old foundation vineyard, which is about 25 years old. Originally the planting in this vineyard was a mixture of healthy registered vines and vines infected with closteroviruses, including the GLRaVs. A mixed planting of healthy and virusinfected materials was allowed because the accepted assumption at the time was that the grapevine closteroviruses do not spread from vine to vine. In contrast to the old foundation vineyard, no ELISA-positive vines were found in the more recently established foundation planting known as Brooks vineyard; this planting contained only registered vines. No vines that were known to be virus infected were included when this vineyard was propagated. Most of the vines in Brooks vineyard had originally been

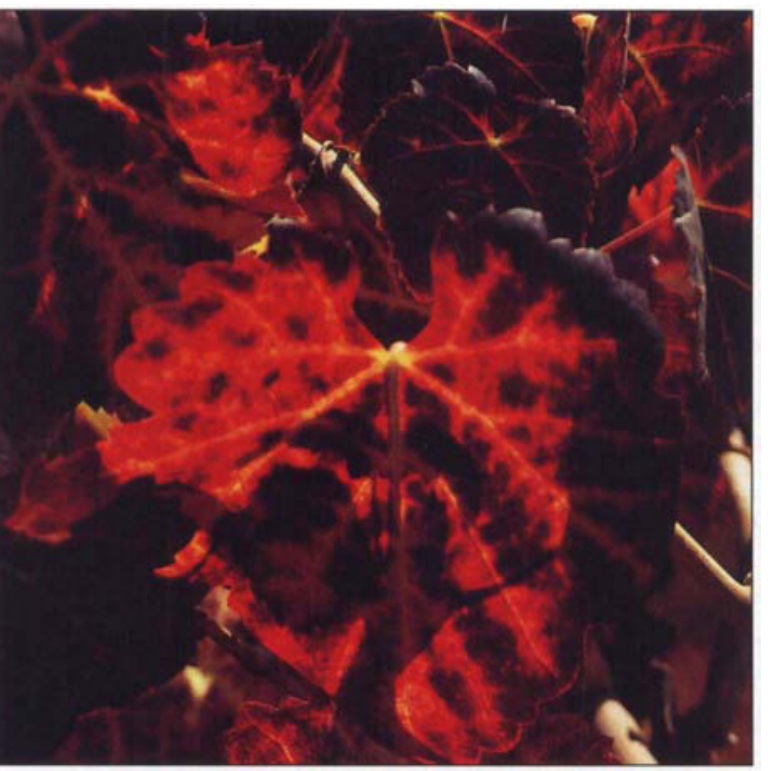

and homogenized by a polytron (Brinkman Instruments Inc.). The extraction buffer was ELISA coating buffer $\left(1.59 \mathrm{~g} \mathrm{Na}_{2} \mathrm{CO}_{3}\right.$ $2.93 \mathrm{~g} \mathrm{NaHCO}_{3}$ in $\left.1 \mathrm{~L}, \mathrm{pH} 9.6\right)$ containing $0.05 \%$ Tween $20,0.2 \%$ bovine serum albumin (BSA) and $2 \%$ polyvinyl pyrrolidone (PVP 40).

The $\mathrm{F}\left(\mathrm{ab}^{\prime}\right)_{2}$ ELISA method was used for GLRaV types II, III and IV as described by Rowhani (American Journal of Enology and Viticulture 43: 38-40). The direct ELISA procedure described by Clark and Adams (Journal of General Virology 34: 475-483) was used for GLRaV type I.

The red color in this Napa Valley Cabernet Sauvignon's leaves in the fall is caused by leafroll disease.

propagated from the old foundation vineyard about 6 years ago. This observation suggests that leafroll has spread in the old foundation vineyard within the last few years.

The discovery of leafroll ELISApositive vines in the foundation vineyard caused serious concern among researchers, regulatory officials, nurserymen and growers. Intensive testing of the entire foundation collection at FPMS was initiated immediately. In addition, extra efforts were directed at standardizing sampling protocols and comparing the results of ELISA tests for grapevine leafroll-associated viruses with the traditional indicator test on 'Cabernet Franc' described earlier.

This article reports the results of tests conducted in 1992 and 1993 as part of an ongoing effort to integrate the leafroll ELISA testing into the FPMS program.

\section{Antisera sources}

Antisera to GLRaV types II, III and IV were produced in cooperation with Dr. Dennis Gonsalves, Cornell University (a joint project funded by the American Vineyard Foundation). Purified and alkaline phosphatase conjugated anti-GLRaV type I were purchased from Bioreba Inc. Samples were bark scrapings collected from different vines in $20 \mathrm{~mL}$ snap-capped bottles containing $5 \mathrm{~mL}$ of extraction buffer (about 1:10 weight to volume)

\section{Standardizing sampling}

To standardize sampling protocols for the new leafroll ELISA test, we tested a group of leafroll-infected vines several times each by ELISA. Samples were collected randomly from four to six branches each time and tested, but inconsistent results were obtained from sample to sample. In an additional test, infected vines were selected, two samples were collected from two different sides of each vine, and each sample was individually ELISA tested. The results revealed that for a few of the tested vines, samples collected from one side were ELISA positive while the opposite side tested negative. These results suggest that in some vines GLRaVs are not distributed uniformly.

\section{Comparisons of tests}

The reliability of field indexing was compared with ELISA tests developed for GLRaV types II and III. ELISAs were performed on indicators used in the annual index of candidate vines for the certification program performed at FPMS. One-year-old 'Cabernet Franc' cuttings grown in 15$\mathrm{cm}$ diameter pots in the greenhouse were graft-inoculated with chip buds of wood obtained from the candidate plants in the late winter of 1989, 1990 and 1991. Two chip buds were grafted into each indicator, with three replicates per selection. These plants were maintained in the greenhouse for 1 to 2 months to allow time for the grafts to 
heal, then they were planted in the field.

In the fall of the second year in the field, the indicator plants were inspected for grapevine leafroll symptoms. During this same period, leaf samples (petioles and leaf base) were taken from each indicator vine and tested by ELISA for GLRaV types II and III (table 1). For the majority of the samples, the results of ELISA testing and the woody index on 'Cabernet Franc' were identical. It is not surprising that some leafroll isolates were detected by indexing and not by ELISA, since several additional GLRaV types that are rare in California have been described and ELISAs for them were not included. In all three experiments conducted in 1989, 1990 and 1991, a positive ELISA result was obtained with tissue from selections that tested negative in the biological index on 'Cabernet Franc'. This suggests that either the Cabernet Franc index is not completely reliable, perhaps due to environmental factors or variation between virus isolates, or that the antisera to types II and III react to some undefined component (possibly part of the leafroll complex) that does not always produce symptoms on 'Cabernet Franc'. Because ELISA tests are used more often to detect leafroll disease as a complement to traditional indexing in grape clean-stock programs, these positive ELISA reactions with indicator-negative grape selections need to be explained.

\section{Testing in 1993}

ELISA tests of the foundation grapevine material for GLRaVs were continued for most of the rootstocks and scion materials for which there is strong industry demand (table 2). The incidence of leafroll-associated viruses was lower in rootstock material $(0.8 \%)$ than in scion material (15.8\%). In addition, the highest incidence of leafroll in scion material was observed in the old foundation vineyard $(29.2 \%)$ as compared to the more recently established Brooks foundation vineyard $(0 \%)$.

\section{Conclusions}

Grapevine leafroll disease is most often transmitted by propagating material from an infected mother plant to progeny. Natural spread of leafroll from infected vines to healthy ones growing nearby has been observed in California, but in the past the rate of spread has been reported to be extremely low. Higher rates of spread have been observed in other grapegrowing regions of the world. Several mealybug species have been shown to transmit leafroll associated viruses under experimental conditions.

Investigations are underway to determine the following: (1) how GLRaVs have spread in foundation

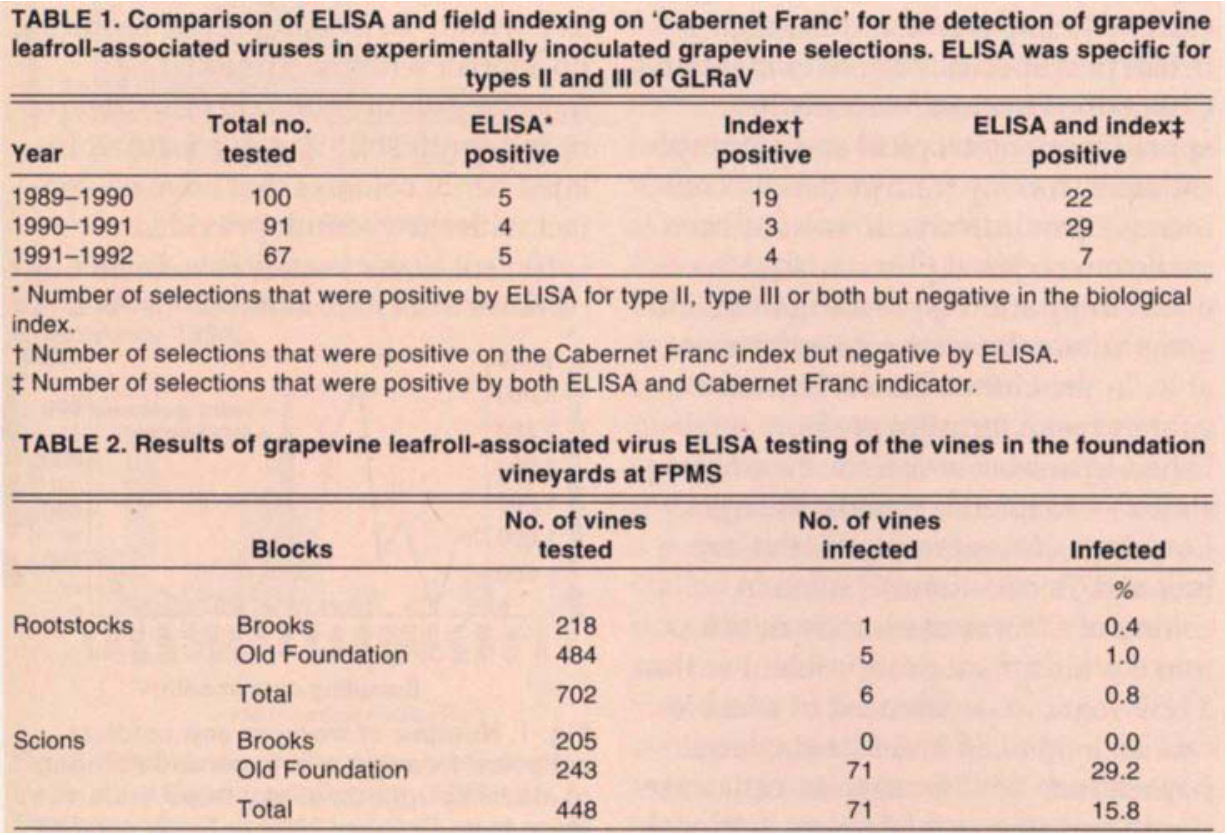

vineyards; (2) the relationship between GLRaVs and leafroll symptoms; (3) the efficacy of ELISA in detecting GLRaVs; and (4) development of a sampling strategy to more accurately detect GLRaVs.

Potential sources of error in the use of the ELISA test for field virus detection of leafroll-associated viruses include variation in test results due to uneven distribution of virus in different tissues; seasonal variation in virus titer; the possible existence of virus strains within different GLRaV types; and the possibility of false negative or false positive reactions brought about by sampling, operator error or faulty reagents. The influence of each of these factors needs to be better understood before testing procedures can be improved.

The discoveries made about leafroll disease in the foundation grapevine plantings at FPMS will be considered in modifying the procedures and protocols used to produce California certified grapevines. ELISA-positive vines will be eliminated from the program. The foundation vineyard has been reorganized to include only vines that test ELISA negative for leafroll-associated viruses. Although this may result in a short-term shortage of a few selections for nursery registration blocks, ultimately the program will be stronger. Research in this area will continue to provide advances in virus-detection technology to increase standards and improve the quality of the program.

A. Rowhani is Specialist, Department of Plant Pathology, UC Davis, and D.A. Golino was Research Plant Pathologist, USDA-ARS, Department of Plant Pathology, UC Davis and is now Director, Foundation Plant Materials Service, UC Davis. This study was supported in part by the California Department of Food and Agriculture, the American Vineyard Foundation, the California Table Grape Commission, the California Raisin Advisory Board and the Fruit Tree, Nut Tree, and Grapevine Improvement Advisory Board. The assistance with indexing by Mike Cunningham, Foundation Plant Materials Service, UC Davis, is gratefully acknowledged. 